\title{
Traditional Anticoagulants and Hair Loss: A Role for Direct Oral Anticoagulants? A Review of the Literature
}

\author{
Magdalena M. Watras ${ }^{1} \cdot$ Jignesh P. Patel ${ }^{2,3} \cdot$ Roopen Arya $^{2}$
}

Published online: 7 January 2016

(C) The Author(s) 2016. This article is published with open access at Springerlink.com

\begin{abstract}
Hair loss is associated with the anticoagulants heparin and warfarin. With the recent availability of direct oral anticoagulants (DOACs) it is of clinical interest to know if they are implicated with hair loss and/or whether they could be successfully prescribed for patients who suffer from coumarin- or heparin-related alopecia. Initially reports of heparin- and coumarin-associated alopecia available through PubMed and Medline were explored in order to establish the cause of this side effect. Currently there is a lack of unanimity on why anticoagulants cause alopecia. However, timing and presentation strongly suggest that telogen effluvium is part of the process. The observation that both heparins and coumarins cause a similar pattern of hair loss suggests a shared mechanism related to anticoagulant activity. To date, the World Health Organization has received 405 reports of DOAC-associated alopecia through their pharmacovigilance database VigiBase $^{\circledR}$. Additionally, real world registry data describes an alopecia incidence of 4.4 per 100 patient years in patients prescribed rivaroxaban and dabigatran. Further widespread clinical experience is required to ascertain if this is true, but early indications suggest that DOACs are implicated in hair loss and will not provide a suitable alternative for patients suffering from alopecia related to traditional anticoagulants.
\end{abstract}

Magdalena M. Watras

magdalena.watras@nhs.net

1 Pharmacy Department, King's College Hospital, Denmark Hill, London SE5 9RS, UK

2 King's Thrombosis Centre, Department of Haematological Medicine, King's College Hospital, London, UK

3 Institute of Pharmaceutical Science, King's College London, London, UK

\section{Key Points}

Traditional anticoagulants are known to cause hair loss and the mechanism is likely to be related to their therapeutic activity.

Early experience with direct oral anticoagulants suggests that they are also implicated in this side effect and therefore do not offer an alternative to patients experiencing alopecia due to treatment with coumarins or heparins.

\section{Background}

Many drugs are associated with hair loss but rarely is the causation as certain as that seen with cancer chemotherapy or sodium valproate [1]. Hair loss, or alopecia, associated with drug use is often considered an idiosyncratic adverse effect of uncertain mechanism. Reports of alopecia linked to the use of anticoagulants date back to shortly after their clinical use became widespread and began to emerge in the 1950 s, first with unfractionated heparin and then with oral coumarins, with reported incidences of 54-66 and $30-40 \%$, respectively $[2,3]$. Since then, all anticoagulants have been implicated in causing alopecia to some extent. Table 1 lists the cases and reports which have been published in the literature to date. Despite the high reported incidence of anticoagulant-related alopecia and the volume of anticoagulant use, the database of the World Health Organization (WHO)-Uppsala Monitoring Centre (UMC) VigiBase ${ }^{\circledR}$ has on record 877 cases of alopecia related to warfarin, 105 to acenocoumarol and 2 to phenindione [4]. 
Table 1 Published case reports linking increase in hair loss with anticoagulants (presented in chronological order)

\begin{tabular}{|c|c|c|c|c|c|c|}
\hline $\begin{array}{l}\text { Age } \\
\text { (years) }\end{array}$ & Sex & Drug & Indication for anticoagulation & $\begin{array}{l}\text { Treatment duration until } \\
\text { report of hair loss }\end{array}$ & Year & Refs \\
\hline 2 & $\mathrm{~F}$ & Warfarin & Accidental ingestion & 2.5 weeks & 1957 & [9] \\
\hline 43 & M & Heparin & Thrombophebitis & 2 months & 1965 & [7] \\
\hline 6 & M & Warfarin & Chronic accidental ingestion & Unknown & 1965 & [7] \\
\hline 62 & $\mathrm{~F}$ & Warfarin & Mitral valve replacement & 10 years & 1988 & [10] \\
\hline 55 & M & Warfarin & Aortic valve replacement & 13 years & 1988 & {$[10]$} \\
\hline 65 & $\mathrm{~F}$ & Warfarin & Mitral valve replacement & 1.5 years & 1988 & {$[10]$} \\
\hline 35 & M & Warfarin & Aortic valve replacement & 5 years & 1993 & {$[11]$} \\
\hline 57 & $\mathrm{~F}$ & Warfarin & Cardiogenic brain embolism & 2 months & 1995 & [11] \\
\hline 49 & $\mathrm{~F}$ & Warfarin & Systemic lupus erythematosus & 2 months & 1995 & {$[12]$} \\
\hline 9 & $\mathrm{~F}$ & Dalteparin & Sinus venous thrombosis & 2.5 months & 2000 & {$[16]$} \\
\hline 62 & M & Acenocoumarol & Post MI to prevent aneurysm & 2 months & 2000 & {$[15]$} \\
\hline 65 & M & Acenocoumarol & Cardioembolic stroke & 2 months & 2000 & {$[15]$} \\
\hline 60 & $\mathrm{~F}$ & Acenocoumarol & Valve prosthesis & 16 months & 2000 & {$[15]$} \\
\hline 69 & $\mathrm{~F}$ & Dalteparin & $\begin{array}{l}\text { Prevention of extracorporeal clotting in } \\
\text { haemodialysis }\end{array}$ & $1.5-3$ months & 2001 & {$[15]$} \\
\hline 75 & $\mathrm{~F}$ & Dalteparin & $\begin{array}{l}\text { Prevention of extracorporeal clotting in } \\
\text { haemodialysis }\end{array}$ & $1.5-3$ months & 2001 & [17] \\
\hline 59 & $\mathrm{~F}$ & Dalteparin & $\begin{array}{l}\text { Prevention of extracorporeal clotting in } \\
\text { haemodialysis }\end{array}$ & $1.5-3$ months & 2001 & {$[17]$} \\
\hline 74 & $\mathrm{~F}$ & Dalteparin & $\begin{array}{l}\text { Prevention of extracorporeal clotting in } \\
\text { haemodialysis }\end{array}$ & $1.5-3$ months & 2001 & {$[17]$} \\
\hline 66 & M & Tinzaparin & $\begin{array}{l}\text { Prevention of extracorporeal clotting in } \\
\text { haemodialysis }\end{array}$ & 3 months & 2003 & {$[18]$} \\
\hline 34 & $\mathrm{~F}$ & $\begin{array}{l}\text { Enoxaparin for } 3 \text { weeks then } \\
\text { warfarin }\end{array}$ & Cerebral venous thrombosis & $\begin{array}{l}3 \text { weeks from treatment } \\
\text { start }\end{array}$ & 2006 & [19] \\
\hline 22 & $\mathrm{~F}$ & $\begin{array}{l}\text { Enoxaparin for } 3 \text { weeks then } \\
\text { warfarin }\end{array}$ & Cerebral venous thrombosis & $\begin{array}{l}3 \text { weeks from treatment } \\
\text { start }\end{array}$ & 2006 & [19] \\
\hline 52 & $\mathrm{~F}$ & $\begin{array}{l}\text { Enoxaparin for } 3 \text { weeks then } \\
\text { warfarin }\end{array}$ & Cerebral venous thrombosis & $\begin{array}{l}3 \text { weeks from treatment } \\
\text { start }\end{array}$ & 2006 & [19] \\
\hline 70 & $\mathrm{~F}$ & Warfarin & Deep vein thrombosis & "soon", & 2008 & [13] \\
\hline 25 & M & Warfarin & Pulmonary embolism & 1 month & 2010 & [14] \\
\hline
\end{tabular}

For the heparins, including the low molecular weight heparins, 134 cases are recorded in total. This discrepancy between the early reported incidences and the reports on file at VigiBase ${ }^{\circledR}$ suggests either that alopecia is much less prevalent than initially reported or, more likely, that it is so common that prescribers judge it unnecessary to report, particularly as alopecia is listed as a side effect in the Summary of Product Characteristics for both heparins and warfarin $[5,6]$.

The recent availability of direct oral anticoagulants (DOACs) in clinical practice is leading a paradigm shift in how patients are managed for the acute and long-term treatment of venous thromboembolism and for stroke prophylaxis in the context of atrial fibrillation. The DOACs exert their pharmacological effect on a single coagulation protein in the coagulation cascade and are reported to have less drug-drug and no drug-food interactions compared to the oral courmarins and thus are considered to have predictable pharmacokinetic profiles. Interested readers are referred to Heidbuchel et al. [7] for more details. Given their widespread use in daily practice, it is of interest to know if the DOACs are likely to be implicated in the occurrence of the adverse effect alopecia and thus whether or not they could be successfully prescribed for patients who suffer from coumarin- or heparin-related alopecia.

In order to answer this question, an understanding of hair growth and loss is required.

\section{Hair Growth and Hair Loss}

Hair growth is a cyclical process which consists of three stages. It begins with the growth or anagen phase, during which there is vigorous mitotic activity in the 
hair matrix (part of the hair follicle that produces pigmented cells that make up the structure of the hair) and the hair grows continuously. This phase lasts between a few months and a few years and the duration of the phase dictates the length of the hair. This is followed by a short cessation or catagen phase during which the hair matrix regressively changes as its cells undergo apoptosis. As the hair stops growing, the follicle shortens and the mature hair moves upwards toward the epidermis where it enters the rest or telogen phase [8]. During this resting period, which lasts around 3 months, the hair awaits shedding through either friction such as combing or shampooing or through displacement by newly growing hair underneath. At any given time approximately $85-90 \%$ of hair on the scalp is in the anagen phase, $9-14 \%$ is in the telogen phase, and only $1 \%$ is in the catagen phase. On average around 30-100 hairs will enter each phase per day and approximately that number will be shed. However, the length of each phase and the proportion of hair in each stage varies widely amongst individuals $[9,10]$.

Hair loss can be exacerbated by drugs via two different mechanisms, both affecting the hair in the anagen phase. Cancer chemotherapy, for example, causes anagen effluvium where the cytotoxic agent abruptly arrests hair growth through its antimitotic action. The onset is rapid and as a result anagen hairs fall out in a dystrophic and brittle form within days to weeks of drug exposure. This leads to clinically significant alopecia [8].

The second mechanism, telogen effluvium, is a result of anagen hair shifting into the catagen phase prematurely. When this occurs, the proportion of hair shafts in the resting phase ready to vacate increases, which in turn engenders excessive hair loss. Telogen effluvium can be precipitated by fever, surgery, haemorrhage, childbirth or 'crash' dieting, as well as by drugs [11]. Whether the resulting alopecia is noticeable depends on certain factors: the individual's baseline daily hair loss, how much scalp hair they have and whether or not the increased transition into the catagen phase occurs in a continuous or intermittent manner. The effects are usually visible at around 2-4 months after exposure to the triggering factor. However, telogen effluvium is a dynamic process during which hair loss usually occurs because of emerging hair pushing out hair in the telogen phase. Therefore, if the follicles enter the telogen stage asynchronously as a consequence of chronic exposure to the drug or some other insult, it may take months to years before hair loss is obvious to the patient and alopecia becomes clinically significant $[8,11]$.

\section{Traditional Anticoagulants and Hair Loss}

Traditional anticoagulants are thought to cause hair loss through telogen effluvium, and so alopecia associated with heparins and coumarins may take time to become apparent. In fact, telogen effluvium can frequently go unnoticed, as often hair falling out is due to the re-growth of new hair underneath. Hence, an increase in shedding might not always present as clinically significant alopecia. The latency period between exposure to a drug trigger and increase in hair loss may additionally explain why the phenomenon is under-reported. Finally, there is great interindividual variability in baseline daily hair loss and in density of telogen scalp hair, which dictates whether the increase in rate of loss will lead to cosmetically compromising alopecia [8]. This represents a further complicating factor in determining the extent to which anticoagulants cause an increase in hair loss and alopecia.

A literature search of Embase (1947 to present) and Medline (1946 to present) using terms 'alopecia' or 'hair loss' in conjunction with 'heparin', 'warfarin', 'acenocoumarol', 'phenindione', 'dalteparin', 'enoxaparin' and 'tinazparin' was conducted on the 15 July 2015 and yielded 12 case reports. The first report describes a 2-year-old girl who accidently ingested an unknown amount of the rat poison 'd-con', the active ingredient of which is warfarin. Her mother first noticed hair loss 17 days from the accident which peaked at day 21 . Her hair started re-growing after 31 days [12]. Accidental warfarin ingestion is also reported by Rook [10]: a 6-year-old boy was noted to lose over $50 \%$ of his hair during a 6-month period when he was often observed to play with soil on a farm which used warfarin as rat poison. Rook also describes a more typical case of a 43-year-old man who complained of severe alopecia 3 months after his heparin treatment for thrombophlebitis. Three different cases of alopecia associated with warfarin use post-valve replacement are reported by Umlas and Herken [13] and one by Al-Ibrahim et al. [14]: a 55-year-old man who complained of an increase in hair shedding 13 years after first taking warfarin, a 65 -year-old woman with alopecia appearing 1.5 years into treatment with warfarin and persisting for the duration it is prescribed (14 years), and a 62-year-old woman who only noticed hair loss after 10 years on chronic warfarin therapy; in the latter case, however, the alopecia resolved on discontinuation of anticoagulation and re-appeared on re-challenge [14]. In the case described by Al-Ibrahim et al. [14] the patient presented with alopecia that affected his beard, scalp and moustache 5 years into treatment with warfarin. Two reports were published in the 1990s, a 57-year-old female 
treated with warfarin for cardiogenic brain embolism and a 49-year-old female, positive for lupus anticoagulant and therefore started on warfarin therapy. Both of them complained of increased hair shedding 2 months into treatment [15]. In recent years there have been only two reports of warfarin-associated alopecia: In 2008 a 70-year-old female anticoagulated for deep vein thrombosis $(7 \mathrm{mg} /$ day, no international normalized ratio (INR) target reported) was described to lose patches of previously thick hair soon after commencing treatment [16]. Nakamizo and colleagues [17] describe a 25-year-old man who underwent several cycles of chemotherapy and as a result lost hair all over his body, which then fully regrew 5 months after finishing treatment. He was then treated with warfarin for pulmonary embolism and 1 month into anticoagulant treatment complained of severe diffuse hair loss. The authors speculate that alopecia occurs within 1 month of treatment with warfarin due to an increase in scalp telogen hair post-chemotherapy.

There are three reports of acenocoumarol-associated alopecia published in the literature. In all three cases increase in hair loss is reported within months of starting treatment and it persists for the duration of treatment [18].

The first report of low molecular weight heparin-associated alopecia was in 2000, where a 9-year-old girl who was treated with dalteparin $(100 \mathrm{U} / \mathrm{kg})$ for sinus vein thrombosis noticed extensive hair loss 10 weeks into the treatment. She was on no other medication that could lead to hair loss and it improved 2 weeks after treatment cessation [19]. In 2001, another report was published describing four cases of dalteparin-associated alopecia. Women aged between 59 and 75 year were anticoagulated with dalteparin $(80 \mathrm{IU} / \mathrm{kg}$ ) for prevention of extracorporeal clotting in haemodialysis. They noticed "hair coming out in handfuls" between 6 weeks and 3 months from starting treatment. When the anticoagulation regimen was changed to citrate, hair loss stopped and in one patient that was rechallenged with dalteparin, it re-appeared [20]. Tinzaparin has also been linked to diffuse alopecia in a 66-year-old man who had been on enoxaparin for 9 months and then was switched to tinzaparin for 3 months for prevention of extracorporeal blood clotting. Interestingly, hair loss only occurred with tinzaparin and not enoxaparin. A biopsy of the alopecia area showed "atrophic hair follicle in the papillary dermis and widened follicles filled with keratin fragments" [21]. Wang and colleagues [22], however, describe three cases of females (aged 22-52 years) treated with enoxaparin ( $1 \mathrm{mg} / \mathrm{kg}$ twice a day) and then with warfarin for sinus vein thrombosis who noticed a significant increase in hair loss 3 weeks after commencing treatment with enoxaparin. Dermatologists were consulted and diagnosed telogen effluvium. Interestingly, alopecia ceased during treatment with warfarin (INR target of 2). All three cases were rated 6 on the Naranjo Adverse Drug
Reaction (ADR) probability score and therefore enoxaparin was deemed to be the cause of the alopecia [22].

The published case reports suggest that alopecia is reversible on cessation of treatment and reappears on rechallenge [13, 20]. For warfarin, hair loss is reported to begin after 3 months of treatment, but the time range of onset reported is wide: 2 months to 13 years. Similarly, with heparins, the time of onset is wide, with the average time of onset similar to that reported with warfarin. Despite the fact that spontaneously shed hair was not examined in any of the reported cases, the timing and presentation of hair loss strongly suggests telogen effluvium to be the mechanism.

Age and gender do not affect susceptibility to anticoagulant-induced telogen effluvium [10]. However, there are more published reports in women. This is possibly because of men attributing hair loss to male-pattern baldness. Additionally, females might aggravate the shedding of the resting hair resulting from telogen effluvium by frequent grooming, and therefore increase the rate of loss to a level that produces obvious alopecia.

There is a lack of unanimity over the influence of dose and treatment duration with anticoagulants and the relationship with alopecia. Case reports that implicate oral coumarins in causing telogen effluvium state the dose of the drug that the patients were prescribed, but only two specify the range at which the INR was maintained [14, 15]. Two cases of alopecia were as a result of poisoning with warfarin [10, 12].

For heparins, where the dose has been reported it was either given at therapeutic levels or at low doses for preventing coagulation in the extracorporeal circuit (Table 1). In a study where three groups of patients were given different doses of heparin, heparin and oral anticoagulant, or heparin with an oral anticoagulant, a direct relationship between dose and incidence of hair loss was established [2]. In contrast, in another study a different heparin was given to a total of 240 patients, and alopecia was not apparently related to the total dose received [23].

The specific mechanism behind anticoagulant hair loss caused by anticoagulants is unknown. Most studies simply imply that telogen effluvium is part of the process. Some groups have tried to elucidate the specific mechanism; Kligman [8] took a biopsy of the scalp of patients who experienced alopecia after heparin exposure. Microscopic examination demonstrated that the capillaries of the dermis were variably distended with blood and there was an inconsistent, peculiar focal degeneration of collagen bundles in the vicinity of vessels of the follicular connective sheath. Flesch [24] proposed that the hair entering the resting phase prematurely could be provoked by slow strangling of the hair root and injury to the connective tissue papilla. Currently there is uncertainty whether or not 
the aforementioned change in the vasculature of the scalp is the possible cause of the injury and therefore instrumental in the course of telogen effluvium.

Heparin is also known to possess antimitotic activity, to increase the cohesion of the dermal-epidermal junction in rats [25] and to suppress the proliferation of epithelial bulb in vitro [18]. All these modalities could mediate alopecia, and none is exclusive of the other.

\section{Direct Oral Anticoagulants and Hair Loss}

A literature search of Medline (1946 to present) and Embase (1947 to present) using terms 'alopecia' or 'hair loss' in conjunction with either 'rivaroxaban', 'dabigatran,' 'apixaban' or 'edoxaban' was conducted on 15 July 2015. Out of the three results, one was excluded as the focus of the case report was on fibrinolysis rather than anticoagulants and its side-effects. Of the two valid publications, one was a poster presenting findings from the real-world Dresden DOAC registry. At the time of publishing the poster, the registry held 938 patients who were anticoagulated with either dabigatran or rivaroxaban for over 3 months. During phone follow-up, which was done at day 30 and quarterly thereafter, 12 female patients (age range 21-99 years) spontaneously reported hair loss. The mean treatment duration until the onset of hair loss was $68 \pm 76$ days [26]. As a result, the authors calculated an alopecia incidence of 4.4 per 100 patient years. The final valid publication was a conference abstract presenting findings of a prospective study, which examined the value of follow-up for patients treated with DOACs. Loizou and colleagues [27] followed 37 patients prescribed rivaroxaban (26) or dabigatran (11) over a 12-month period. During that time patients attended the anticoagulation clinics at 2, 4 and 26 weeks into treatment where they were asked about adherence and adverse effects. One out of the 26 patients who were prescribed rivaroxaban had to discontinue the treatment after 2 weeks due to tiredness and hair loss [24].

To date, WHO holds 405 reports of DOAC-associated alopecia on VigiBase $^{\circledR}: 143$ reports for rivaroxaban, 215 for dabigatran, 47 for apixaban and none thus far for edoxaban. In the opinion of the authors, the early indications are that DOACs are implicated in this adverse effect.

\section{Conclusion}

The observation that both heparins and coumarins cause a similar pattern of hair loss suggests a shared mechanism related to their anticoagulant activity. Therefore, one predicts that alopecia will be seen as an adverse effect with the DOACs.
The prevalence is likely to be underestimated by clinicians due to the latency period between drug exposure and development of hair loss. Additionally, whether the resulting increase in hair loss is to a clinically significant level will depend on an individual's baseline hair mass and baseline daily hair loss, which is highly variable from person to person.

Even though not formally reported in the many patients studied in the landmark clinical trials for the DOACs, emerging VigiBase ${ }^{\circledR}$ reports and the early Dresden registry findings suggest that DOACs are implicated. With widerspread clinical use of DOACs this will become clearer. Using algorithmic methods such as Naranjo [28] would help confirm causality, and we call on clinicians worldwide to report alopecia suspected to be related to anticoagulant therapy, so the scale of the problem is fully understood.

\section{Compliance with Ethical Standards}

Conflict of interest Magdalena Watras, Jignesh Patel and Roopen Arya have no conflicts of interest that are directly relevant to the content of this study.

Funding No sources of funding were used to assist in the preparation of this study.

Open Access This article is distributed under the terms of the Creative Commons Attribution-NonCommercial 4.0 International License (http://creativecommons.org/licenses/by-nc/4.0/), which permits any noncommercial use, distribution, and reproduction in any medium, provided you give appropriate credit to the original author(s) and the source, provide a link to the Creative Commons license, and indicate if changes were made.

\section{References}

1. Taylor DM, Paton C, Kapur S. Prescribing guidelines in psychiatry. 12th ed. London: Wiley Blackwell; 2015.

2. Tudhope GR, Cohen H, Meikle RW. Alopecia following treatment with dextran sulphate and other anticoagulant drugs. $\mathrm{Br}$ Med J. 1958;1(5078):1034-7.

3. Fischer R, Bircher J, Reich T. Falling of hair after anticoagulant therapy. Schweiz Med Wochenschr. 1953;83(22):509-11.

4. VigiBase [Online]. Available from: http://www.vigiaccess.org//. Accessed 31 Aug 2015.

5. Summary of Product Characteristics: Warfarin, Amdipharm Mercury Company Limited April 2014. http://www.medicines. org.uk. Accessed 31 Aug 2015.

6. Summary of Product Characteristics: Heparin, Baxter Healthcare Limited. April 2015 . http://www.medicines.org.uk. Accessed 31 Aug 2015.

7. Heidbuchel H, Verhamme P, Alings M, Antz M, Hacke W, Oldgren J, et al. European Heart Rhythm Association practical guide on the use of new oral anticoagulants in patients with nonvalvular atrial fibrillation. Europace. 2013;15(5):625-51.

8. Kligman AM. Pathologic dynamics of human hair loss. I. Telogen effuvium. Archives of dermatology. 1961;83:175-98.

9. Ioannides G. Alopecia: a pathologist's view. Int J Dermatol. 1982;21(6):316-28. 
10. Rook A. Some chemical influences on hair growth and pigmentation. Br J Dermatol. 1965;77:115-29.

11. Pillans PI, Woods DJ. Drug-associated alopecia. International journal of dermatology. 1995;34(3):149-58.

12. Cornbleet T, Hoit L. Alopecia from coumarin. AMA Arch Derm. 1957;75(3):440-1.

13. Umlas J, Harken DE. Warfarin-induced alopecia. Cutis. 1988;42(1):63-4.

14. Al-Ibrahim K, Mohammed Z. Warfarin-induced alopecia: case report and review of the literature. Saudi Heart J. 1993;4(2):71.

15. Nagao $T$, Ibayashi $S$, Fujii $K$, Sugimori $H$, Sadoshima $S$, Fujishima M. Treatment of warfarin-induced hair loss with ubidecarenone. Lancet. 1995;346(8982):1104-5.

16. Leong WA. Case studies in anticoagulation management. J Thromb Thrombolysis. 2008;25(1):78-84.

17. Nakamizo S, Egawa G, Arakawa A, Miyachi Y, Kabashima K. Warfarin-induced alopecia after repeated chemotherapy. Eur J Dermatol EJD. 2010;20(6):828-9.

18. Poquet Jornet J, Pales Argullos A, Portis Espinosa M. Acenocoumarol-induced alopecia: report of three cases. Farm Hosp. 2000;24(5):314-8.

19. Barnes C, Deidun D, Hynes K, Monagle P. Alopecia and dalteparin: a previously unreported association. Blood. 2000;96(4):1618-9.

20. Apsner R, Horl WH, Sunder-Plassmann G. Dalteparin-induced alopecia in hemodialysis patients: reversal by regional citrate anticoagulation. Blood. 2001;97(9):2914-5.
21. Sarris E, Tsele E, Bagiatoudi G, Salpigidis K, Stavrianaki D, Kaklamanis L, et al. Diffuse alopecia in a hemodialysis patient caused by a low-molecular-weight heparin, tinzaparin. Am J Kidney Dis. 2003;41(5):E15.

22. Wang YY, Po HL. Enoxaparin-induced alopecia in patients with cerebral venous thrombosis. J Clin Pharm Thera. 2006;31(5):513-7.

23. Hirschboeck JS, Madison FW, Pisciotta AV. Alopecia and other toxic effects of heparin and synthetic heparinoids. Am J Med Sci. 1954;227(3):279-82.

24. Flesch P. Inhibition of keratinizing structures by systemic drugs. Pharmacol Rev. 1963;15:653-71.

25. Paus R. Hair growth inhibition by heparin in mice: a model system for studying the modulation of epithelial cell growth by glycosaminoglycans? Br J Dermatol. 1991;124(5):415-22.

26. Gelbricht V, Koehler C, Werth S, Haensel U, Schreier T, Luise T, et al. Hair loss is a potential side effect of novel oral anticoagulants-findings from the dresden noac registry (NCT01588119). Blood. 2012;120(21).

27. Loizou E, Toh C-H, Dutt T. Safe implementation of the new oral anticoagulants (NOACs) requires patient monitoring. J Thromb Haemostasis. 2014;12(9):1538-7933.

28. Naranjo C, Busto U, Sellers E, Sandor P, Ruiz I, Roberts E, et al. A method for estimating the probability of adverse drug reactions. Clin Pharmacol Ther. 1981;30(2):239-45. 